\title{
Continuous fetal monitoring in the ambulant patient in labour
}

\author{
ANNA FLYNN, JOHN KELLY
}

British Medical fournal, 1976, 2, 842-843

\section{Summary}

Fetal heart rate was monitored continuously in 30 ambulant women in labour by radiotelemetry. The procedure was practicable and, since contractions were less uncomfortable with the patient standing or walking about, reduced the need for analgesia. It also resulted in a more natural labour. Use of the procedure may lessen the risk of thromboembolism.

\section{Introduction}

Continuous fetal heart rate monitoring in labour has played an important part in reducing perinatal mortality, ${ }_{1}{ }^{2}$ but with present methods of monitoring the mother is confined to bed. Smellie $^{3}$ mentioned the value of being out of bed in early labour. Uterine action has been shown to be more efficient in the lateral position than the dorsal position. ${ }^{4}$ Mendez-Bauer ${ }^{5}$ compared the supine with the standing position in labour and not only found better uterine action while standing but also found that the patient experienced less pain with uterine contractions and was more comfortable in this position.

We report a system for continuous fetal heart rate monitoring in labour that allows the patient to be ambulant.

\section{Patients and methods}

Thirty patients were studied, 18 normal and 12 "at risk"; 10 were gravida I, 14 gravida II, and 6 gravida III. Labour was spontaneous in 27 and induced in three.

An electrode was applied to the fetal scalp with the patient in the left lateral position or tilted $20^{\circ}$. The membranes had ruptured spontaneously in 18 patients, and in the remainder forewater amniotomy was performed when the electrode was applied. From a small battery-operated transmitter (Hewlett-Packard 78100A) attached to the leads of the scalp electrode and worn round the patient's waist (fig 1) the fetal electrocardiogram was radioed to a receiver (Hewlett-Packard 78101A). This was connected to a display unit (chart recorder and oscilloscope) (fig 2) situated at the point most convenient for the midwife, usually the nurses' central station. The fetal heart rate was thus always under surveillance wherever the patient walked. The system has a range of at least 200 metres and worked with the transmitter and receiver three floors apart.

The patient wore a sterile sanitary pad and was free to walk around, sit and chat, or watch television in the day room. Relatives were encouraged to remain with the patient if desired. Whenever the patient wanted to lie down she was taken back to bed. All patients were returned to bed for the second stage. Strength, duration, and frequency of uterine contractions were assessed by palpation.

\section{Results}

A satisfactory, readable record was obtained in all cases with little signal interference. The mean duration of labour was 5 (range 3-11)

Birmingham Maternity Hospital, Queen Elizabeth Medical Centre, Birmingham B15 2TG

ANNA FLYNN, DPH, MRCOG, research fellow in perinatology

JOHN KELLY, FRCSED, FRCOG, consultant obstetrician and gynaecologist

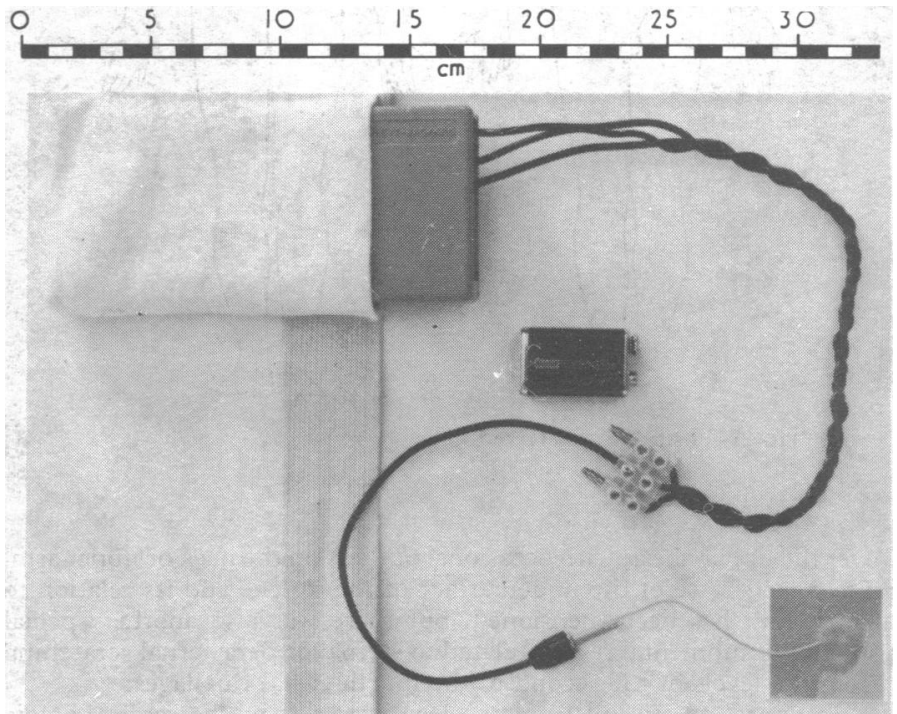

FIG 1-Transmitter, low-cost mercury battery, scalp electrode terminals and belt with pocket for transmitter.

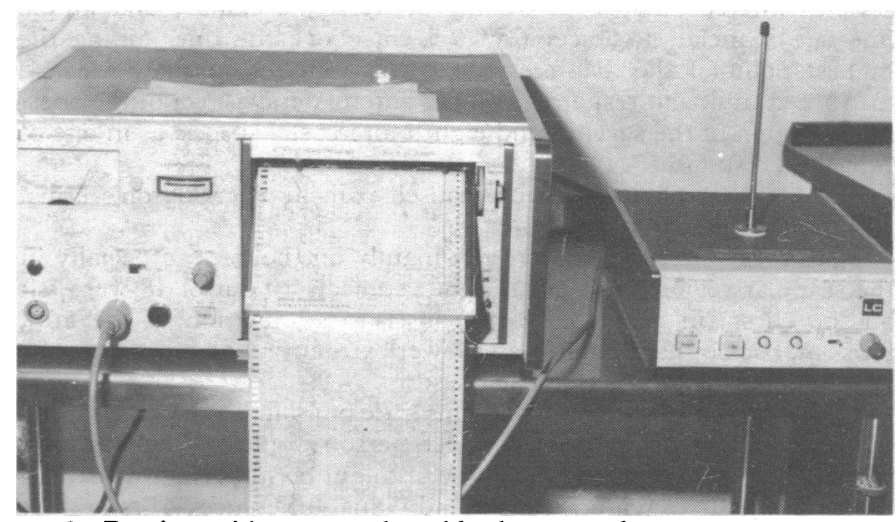

FIG 2-Receiver with antenna alongside chart recorder.

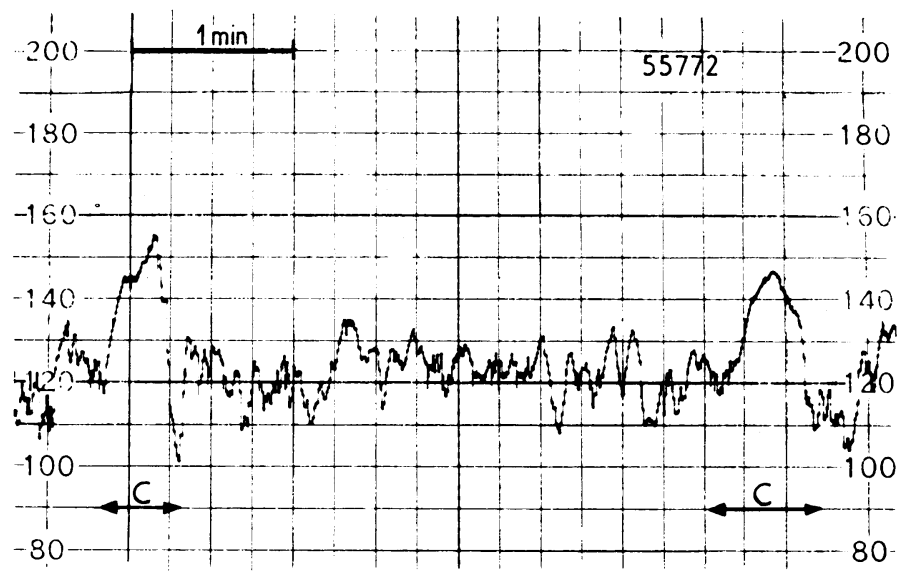

FIG 3-Accelerations in fetal heart rate in response to contractions (C). Duration of accelerations vary with duration of contractions. 
hours and of ambulation 2 (range $0 \cdot 5-5$ ) hours. Intravenous fluids (dextrose) were given to two patients; none required oxytocics. All patients who were questioned 24 hours after delivery were completely satisfied with their labour, and 24 would have liked to have been ambulant longer, as they believed that their contractions were more comfortable when standing or walking than when sitting or lying in bed. Staff were equally enthusiastic because of the "naturalness" of the labour process. There were no cases of puerperal pyrexia or neonatal infection.

There were 28 normal deliveries. Outlet forceps were used on two occasions for failure to advance in the second stage. Whenever analgesia was required the patient was returned to bed. Eight patients received pethidine, two $50 \mathrm{mg}$, four $100 \mathrm{mg}$, and two $150 \mathrm{mg}$. The others needed no analgesia or inhaled nitrous oxide and oxygen for short periods in the second stage. All infants were well; the mean Apgar score was 8.87 at one minute and 9.93 at five minutes.

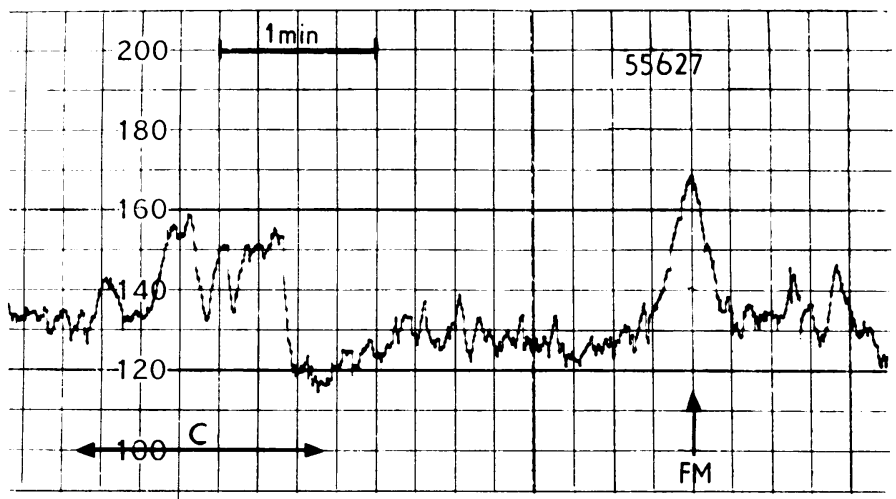

FIG 4-Accelerations in fetal heart rate in response to contractions (C) and fetal movement (FM).
Figures 3 and 4 are examples of the fetal heart rate record. All records were normal apart from early deceleration in two cases and tachycardia in five-all just before the beginning of the second stage.

\section{Discussion}

Until now, because of technical limitations, continuous fetal monitoring in labour has meant confining the patient to bed. With our system of radiotelemetry traces of high quality were obtained with the patient ambulant. Keeping the mother immobilised in bed connected to various types of apparatusfor example, intravenous fluids, intrauterine pressure catheter, and fetal heart rate monitor-may impair the affectional bond between mother and infant. ${ }^{6}$; The reduced need for analgesia and the naturalness of labour with the patient ambulant might be expected to increase the development of this bond and to decrease the incidence of thromboembolism.

\section{References}

${ }^{1}$ Paul, $\mathrm{R} \mathrm{H}$, in Proceedings of the Neonatal Intensive Care Conference, ed J Dancis. New York, Wiley, 1975.

${ }^{2}$ Shenker, L, American fournal of Obstetrics and Gynecology, 1973, 115, 1111.

${ }^{3}$ Smellie, W, Treatise on the Theory and Practice of Midwifery, ed A $\mathbf{H}$ McLintock, vol 2, p 160. London, New Sydenham Society, 1876.

${ }^{4}$ Caldeyro-Barcia, R L, et al, American fournal of Obstetrics and Gynecology, $1960,80,284$.

${ }^{5}$ Mendez-Bauer, C, et al, Perinatal Medicine, 1975, 3, 89.

6. Kennell, J H, Trause, M A, and Klaus, M H, Ciba Foundation, ParentInfant Interaction. (symposium 33, new series). Amsterdam and New York, Association of Scientific Publishers, 1975.

${ }^{7}$ Dunn, P M, Lancet, 1976, 1, 790.

\title{
CONDENSED REPORTS
}

\section{Regional variations in need for and provision and use of child health services in England and Wales}

\author{
R R WEST, C R LOWE
}

their use statistics indicate needs, whereas they really indicate met demands. It is more important to identify demands and needs that are not being met.

\section{Summary}

An analysis of indicators of the need for and provision and use of child health services in the 15 pre-1974 hospital board regions in England and Wales showed that need and provision were badly matched. There was a high degree of correlation between the indices within each of the three groups, indicating that a region with a small provision in one area of child health services would tend to have few resources in other areas also. Statistics on the use of services relate more to the provision of those services than to the need for them. Regions with large resources will justify these resources by claiming that

\footnotetext{
Department of Community Medicine, Welsh National School of Medicine, Cardiff CF4 4XN

R R WEST, MA, PHD, lecturer

C R LOWE, MD, FRCP, professor
}

\section{Introduction}

In England and Wales both general death rates and diseasespecific death rates vary greatly from region to region. ${ }^{1-4}$ Broadly, the rates are much higher in the north-west than in the south-east. This has been so for a long time: William Farr drew attention to it in the early issues of the Registrar General's annual report more than a century ago. ${ }^{5}$ One of the objectives of the National Health Service Act in 1946 was to ensure that everybody in the community-irrespective of means, age, sex, or occupation-should have equal opportunity to benefit from the best and most up-to-date medical and allied services available. Yet 30 years later regional differences in mortality persist, as do the differences in the provision of health service resources, whether measured in terms of hospital beds, annual hospital expenditure, community services, or total area health authority expenditure ${ }^{6-10}$ Indeed, what Titmus called territorial justice (more equality of access to medical care services for people 